DOI:10.33099/2311-7249/2019-34-1-133-138

УДК 519.81

Наталія Олександрівна Королюк (кандидат технічних наук) ${ }^{1}$

Роман Олексійович Пазинич ${ }^{2}$

Сергій В'ячеславович Мельник ${ }^{3}$

${ }^{1}$ Харківський національний університет Повітряних Сил ім. І. Кожедуба, Харків, Украӥна

2 в/и А1671, Чернігів, Украӥна

${ }^{3}$ в/и A0351, Київ, Украӥна

\title{
ОБҐРУНТУВАННЯ КОМПЛЕКСНОГО ПІДХОДУ ДЛЯ ОЦІНКИ ЕФЕКТИВНОСТІ УПРАВЛІННЯ ЧАСТИНАМИ ТА ПІДРОЗДІЛАМИ ПОВІТРЯНИХ СИЛ ЗСУ
}

\begin{abstract}
У статті запропонований комплексний підхід для оичінки ефективності функиіонування системи управління підрозділами Повітряних Сил Збройних Сил Украйни з урахуванням факторів, щуо впливають на функиіонування, вимог, щзо висуваються, досвіду організації управління. Рекомендовано завдання оцінки ефективності функиіонування системи управління розглядати як процес ухвалення рімень по декількох показників. Проте реалізація изього підходу передбачає формування залежності результуючого показника від безлічі часткових, які характеризують відповідність системи управління своєму призначенню. Пропонується використання методів аналізу функиіональних характеристик системи управління $i$ побудови системи показників відповідно до функиій об'єкта дослідження. В якості формальної математичної конструкиії використовується дерево иілей системи. Обгрунтований комплексний показник, щуо характеризує ефективність системи управління, щуо визначається точносними, тимчасовими або імовірнісними характеристиками правильного рімення.

Ключові слова: ефективність управління, узагальнений показник якості управління, дерево цілей, системи управління.
\end{abstract}

\section{Вступ}

Постановка проблеми. Досвід локальних війн та конфліктів останнього десятиріччя свідчить, що угруповання сил та засобів повітряного нападу здатні виконувати як оперативно-тактичні, так і стратегічні завдання. Це обумовлює підвищення значення боротьби у повітряному просторі для досягнення успіху не лише в окремих операціях збройних сил, але й у війні в цілому [1-2]. Зростання ролі авіації у воєнній сфері підтверджується об' єктивними закономірностями, в основі яких лежить зростання обсягу завдань авіаційних угруповань в сучасних операціях (бойових діях).

Аналіз застосування сил і засобів збройної боротьби в ході останніх збройних конфліктів свідчить, що основною тенденцією застосування військ (сил) є перехід від концепції “платформоцентричної війни”, де основний акцент робився на кількість озброєння та військової техніки, у бік "мережецентричних війн”, основою яких $\epsilon$ інтеграція всіх сил i засобів у єдиному інформаційному просторі, що дозволяє суттєво підвищити ефективність їх бойового застосування за рахунок зменшення тривалості циклу бойового управління [3-4]. При цьому, підвищення ефективності управління можливе за рахунок практичної організації єдиного бойового управління всіма військами і силами авіації i протиповітряної оборони (ППО), що не завжди реалізовувалось в минулому.
Аналіз останніх досліджень і публікацій. Питанням дослідження ефективності складних систем управління (СУ) присвячено ряд публікацій [5-8]. Їх аналіз показує, що в якості методичної основи при проведенні досліджень складних систем нині застосовується методологія системного аналізу, що використовує поняття, концепції, формально-математичний апарат кібернетики i теорії складних систем. Оцінка ефективності систем управління частинами (підрозділами) повинна здійснюватися на основі аналізу специфіки їх функціонування.

Дослідження та оцінка ефективності функціонування системи управління, не дивлячись на достатню кількість публікацій та наукових досліджень $є$ досить складним теоретичним i практичним завданням. При обгрунтуванні підходів для оцінки ефективності управління частинами та підрозділами Повітряних Сил ЗСУ необхідно враховувати особливості:

невизначеності в діях повітряного противника, його ініціативи у виборі способів застосування засобів повітряного нападу (ЗПН), наявності у нього сучасної високоточної зброї та засобів радіоелектронної боротьби (РЕБ);

застосування концепцій безконтактних (гібридних) війн 3 однієї сторони та застарілим озброєнням та військовою технікою (ОВТ), недостатнім інформаційним забезпеченням, великим часом реакції системи ППО 3 іншої сторони. 
Однак аналіз існуючих методик демонструє, що нині існує декілька підходів для дослідження і оцінки ефективності управління частинами (підрозділами). Перший підхід полягає в оцінці ефективності бойового застосування частин. У другому випадку, оцінка ефективності управління здійснюється виходячи 3 аналізу ефективності функціонування СУ, в ході рішення завдань 3 управління в заданому діапазоні умов застосування.

Мета статті. Обгрунтування комплексного підходу для оцінки ефективності управління частинами, підрозділами Повітряних Сил Збройних Сил 3 урахуванням факторів, що впливають на функціонування СУ, вимог що висуваються, досвіду організації управління та вимог керівних документів.

3 метою досягнення поставленої мети доцільно вирішити часткові завдання:

- аналіз факторів, які впливають на ефективність управління частинами, підрозділами ПС ЗС під час ведення бойових дій;

\section{- дослідження}

автоматизованого підрозділами ПС 3С;

- обгрунтування управління

ефективності частинами, комплексного підходу для оцінки ефективності функціонування СУ частинами, підрозділами Повітряних Сил Збройних Сил.

\section{Виклад основного матеріалу дослідження}

Управління - безперервний послідовний організаційно-технічний процес, що здійснюється iз широким використанням різноманітного впливу суб'єкта на об'єкт управління для досягнення заданої мети. Це особлива діяльність керівного складу, яка проводиться на основі інформації про стан зовнішнього середовища, об'єкта управління.

Основною метою управління $є$ максимальна реалізація потенційних можливостей підпорядкованих сил в інтересах досягнення у встановлені строки задач в операції, на основі виробки і реалізації сучасних та обгрунтованих рішень 3 урахуванням конкретних умов обстановки та з мінімальними втратами [9].

Управління частинами та підрозділами Повітряних Сил - це цілеспрямована діяльність командирів, штабів, органів управління щодо підтримання бойової та мобілізаційної готовності частин (підрозділів) їх підготовки до бойових дій та керівництва ними під час виконання поставлених завдань.

При цьому, найважливішими принципами управління частинами є: єдиноначальність; централізація у всіх ланках 3 наданням підлеглим ініціативи у визначенні способів виконання поставлених завдань; твердість і наполегливість у впровадженні в життя прийнятих рішень і планів; оперативне i гнучке реагування на зміну обстановки; особиста відповідальність командирів i начальників за прийняті рішення, використання підпорядкованих підрозділів і результати виконання поставлених їм завдань.
Інформаційне забезпечення при підготовці та в ході ведення операції буде характеризуватись напруженими потоками інформації між різними органами управління. Інформаційні потоки будуть залежати від стану елементів СУ та іiі організаційної структури.

Функції управління повинні включати завдання забезпечення адекватності інформації, що сприймається органами військового управління, відповідати цілям ведення операції на оперативному рівні, а також завданням достовірного відображення стану зовнішнього середовища, системі й об'єктам управління.

3 огляду на останні тенденції створення СУ бойовими діями авіації та ППО країн Альянсу, в Республіці Польща розгорнута система управління у відповідності до структури та вимог ACCS на базі національної АСУ “Дунай”. Обмін інформацією забезпечується в єдиному стандарті передачі даних НАТО "link 1". В Германії компанія ESG (Elektroniksistem und Logistik) розробила мобільний командний пункт (КП) для військово-повітряних сил (ВПС), що застосовуватиметься для управління як окремими підрозділами, так і ВПС в цілому.

Отже, в збройних силах країн НАТО та США, удосконалення СУ частин та підрозділів Повітряних Сил здійснюється шляхом підвищення мобільності пунктів управління (ПУ), формуванням єдиного поля бойового управління авіацією й засобами ППО, використання принципів модульності ПУ та відкритості архітектури систем.

Таким чином, ефективність управління залежить як від підготовленості бойової обслуги, автоматизації процесів управління, так і від раціональної побудови всієї системи, комплексного підходу до підвищення ефективності управління. Необхідно застосовувати сучасні розробки та сучасну технічну базу, враховувати останні тенденції розвитку СУ збройних сил провідних країн світу.

Виходячи із вимог до управління, спостерігається певна залежність ефективності управління від таких факторів: своєчасність прийняття рішення; чіткість постановки задач підпорядкованим силам; якість і оперативність використання інформації яка є в наявності; висока готовність органів управління; комплексне використання технічних засобів управління; суворе виконання правил скритного управління військами і безпеки зв'язку; забезпечення живучості ПУ; надійний захист від засобів радіоелектронного подавлення (РЕП) противника.

У загальному випадку під ефективністю управління розуміється вплив системи управління на досягнення кінцевих цілей бойових дій або на ступінь використання в операції потенційних бойових можливостей військ в конкретній обстановці.

Кількісно ефективність системи може бути оцінена з використанням показників ефективності - чисельної міри. Порівняння кількісних 134 ISSN2311-7249(Print)/ISSN2410-7336(Onfine) Сучасні інббормахійні технолосіїу сббері безпеки та оборони № 1(34)/2019 
показників систем дозволяє говорити про те, наскільки (чи в скільки разів) одна система краще (чи гірше) за іншу за тим або іншим показником, або наскільки одна система ефективніша за іншу.

Одним 3 головних завдань при оцінці ефективності складних систем $€$ формування i постійне вдосконалення системи показників, адекватних до тих, що відтворюють основні властивості систем які оцінюються.

Дослідження та оцінка ефективності функціонування СУ, не дивлячись на достатню кількість публікацій та наукових досліджень $є$ досить складним теоретичним i практичним завданням та потребує виконання ряду етапів, які представлені на рис.1 [5-11].

В процесі функціонування системи управління відбувається зміна ііі станів (рух у просторі станів) у зв'язку 3 впливом зовнішніх та внутрішніх факторів. Тому процедура оцінки ефективності системи управління буде носити характер прогнозування результату функціонування систем [5].

На практиці, в ході рішення завдань, пов'язаних 3 оцінкою бойових можливостей СУ, прагнуть використати один узагальнений показник, що інтегрально оцінює вплив СУ на ефективність застосування військ.

Проте використання узагальненого показника пов'язане 3 різного роду труднощами, обумовленими як складністю обліку в структурі такого показника усієї сукупності чинників, що впливають на нього, так i можливістю його отримання в ході експериментальних досліджень. Це призводить до того, що при комплексному дослідженні ефективності бойових дій, використовується сукупність показників, вибір яких визначається завданнями, що вирішуються.

Отже, оцінка ефективності СУ має розраховуватись по сукупності показників внутрішньої (функціональної) і зовнішньої (бойової) ефективності.

При цьому часткові показники внутрішньої ефективності системи ні формально, ні функціонально не пов'язані 3 показником зовнішної ефективності. 3 урахуванням усунення невизначеностей, характерних для наведеного підходу, доцільно розглянути варіант побудови системи критеріїв (показників) ефективності управління, заснований на типових етапах функціонування СУ [4; 10].

Оцінка внутрішньої ефективності управління буде складатися із оцінки якості управління i таких властивостей системи управління як бойова готовність, оперативність, стійкість, безперервність і скритність.

В якості показників бойової ефективності зазвичай використовуються узагальнені показники якості управління (ПЯУ).

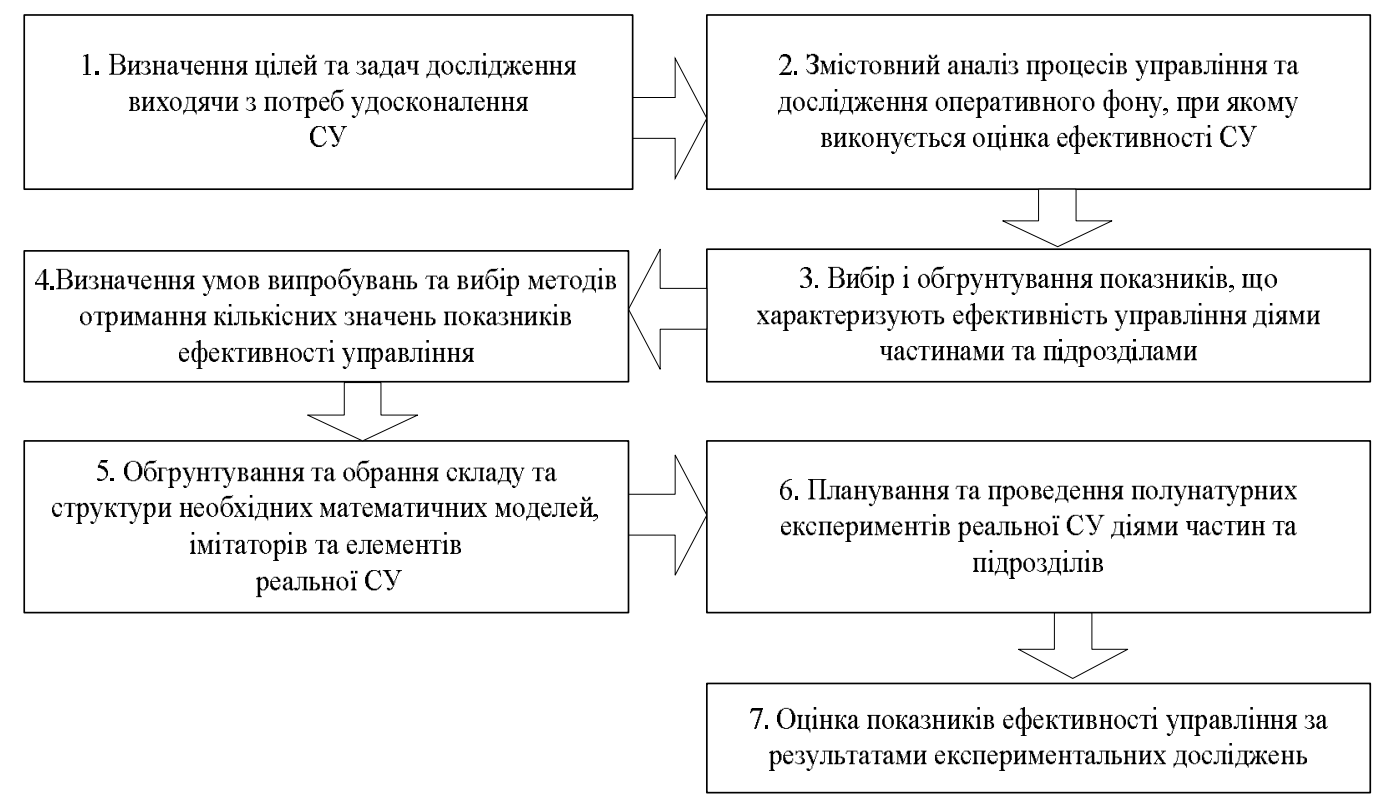

Рис. 1 Етапи проведення дослідження та оцінки ефективності системи управління

Традиційно в узагальненому аналітичному вигляді ПЯУ оцінюється як величина відшкодованого збитку, що наноситься об'єктам оборони, а саме:

$$
\mathrm{Q}=\sum_{\mathrm{r}=1}^{\mathrm{R}} \mathrm{C}_{\mathrm{r}}\left(\sum_{\mathrm{j}=1}^{\mathrm{N}} \mathrm{C}_{\mathrm{rj}} \mathrm{P}_{\mathrm{rj}}^{3 \mathrm{O}}-\sum_{\mathrm{j}=1}^{\mathrm{N}} \sum_{\mathrm{i}=1}^{\mathrm{M}} \mathrm{C}_{\mathrm{rj}} \mathrm{P}_{\mathrm{rj}}^{3 \mathrm{O}} \mathrm{P}_{\mathrm{ij}}^{\mathrm{E3}} \mathrm{m}_{\mathrm{ij}}\right)
$$

де $\mathrm{C}_{\mathrm{r}}-$ важливість r-окремого об'єкта, що обороняється;

r, R - номери об'єктів, що обороняються;
$\mathrm{C}_{\mathrm{rj}}$ - коефіцієнт важливості (небезпечності) $\mathrm{j}-\mathrm{i}$ цілі для $\mathrm{r}$-го об'єкта оборони;

$\mathrm{P}_{\mathrm{rj}}^{3 \mathrm{O}}$ - імовірність входу j-ї цілі в зону небезпеки $\mathrm{r}$-го об'єкта оборони;

$\mathrm{N}$ - кількість цілей в ударі;

М - кількість вогневих засобів;

$\mathrm{P}_{\mathrm{ij}}^{\text {Б3 }}$ - імовірність виконання i -м вогневим засобом бойової задачі по ј-й цілі; 
$\mathrm{m}_{\mathrm{ij}}$ - параметр управління, що характеризує функціонування СУ:

Дослідження ефективності 3 використанням показника відверненого збитку дозволяє отримати підсумкову оцінку якості управління і спростити порівняльну оцінку ефективності систем управління однакового цільового призначення.

Проте набуття кількісних значень показників ефективності з використанням виразу (1) є досить складним завданням, пов'язаним 3 необхідністю визначення параметрів, що характеризують стан об'єктів, які прикриваються $\mathrm{C}_{\mathrm{r}}$, i повітряних цілей $\mathrm{C}_{\mathrm{rj}}$. На практиці величину відверненого збитку визначають шляхом математичного моделювання бойових дій.

Для оцінки якості управління бойовими діями авіаційних частин (підрозділів) ряд методик в якості показника використовує математичне очікування числа знищених цілей:

$$
\mathrm{M}_{Ц}=\mathrm{K}_{\text {БГ }}^{\mathrm{P}} \mathrm{K}_{\text {уП }}^{\mathrm{P}} \mathrm{N}^{\mathrm{B} 3} \sum_{\mathrm{k}=1}^{\frac{\mathrm{n}_{\mathrm{p}}^{\mathrm{n}}}{\mathrm{n}_{\mathrm{p}}^{1}}} \mathrm{P}_{\mathrm{k}}^{\mathrm{p}}\left(1-\left(1-\mathrm{P}_{\text {ураж }}^{\mathrm{P}}\right)^{\mathrm{n}_{\mathrm{p}}^{1}}\right) \mathrm{P}_{\mathrm{Hk}}^{\mathrm{P}}
$$

де $\mathrm{n}_{\mathrm{p}}^{\mathrm{n}}, \mathrm{n}_{\mathrm{p}}^{1}-$ кількість ракет на вогневому засобі заданого типу авіаційної частини і ракет, що застосовується ними в одній атаці;

$\mathrm{P}_{\mathrm{k}}^{\mathrm{p}}$ - розрахункова імовірність реалізації -і атаки в залежності від надійності і живучості;

$\mathrm{P}_{\text {ураж }}^{\mathrm{P}}$ - розрахункова імовірність ураження цілі при пуску однієї ракети кожним типом вогневого засобу;

$\mathrm{P}_{\mathrm{Hk}}^{\mathrm{P}}-$ розрахункова імовірність наведення ракети на ціль в k -й атаці;

$\mathrm{K}_{\text {БГ }}^{\mathrm{P}}-$ розрахунковий коефіцієнт боєготовності вогневих засобів;

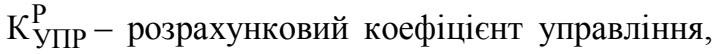
що враховує підвищення (зниження) ефективності застосування за рахунок якості управління;

$\mathrm{N}^{\mathrm{B} 3}$ - кількість вогневих засобів.

Параметри, що безпосередньо характеризують ефективність функціонування СУ $\mathrm{m}_{\mathrm{ij}}$ та $\mathrm{K}_{\text {УПР }}^{\mathrm{P}}$ ототожнюються тільки 3 показником якості цілерозподілення, що, в загальному випадку, неприпустимо. Управління бойовими діями не зводиться лише до цілерозподілення, а $є$ цілим комплексом заходів, що включає питання планування, організації i управління підпорядкованими силами (засобами).

Пропонується використання методів аналізу функціональних характеристик СУ i побудови системи показників відповідно до функцій (завдань, що вирішуються) об'єктом дослідження. Для вирішення цього завдання, в якості формальної математичної конструкції використовується дерево цілей системи.

Дерево цілей відображує ієрархію завдань, що стоять перед СУ, і визначає взаємозв'язок між елементами різних рівнів управління. Ієрархічна структура дерева цілей дозволяє формалізувати процес вибору і побудови системи показників для оцінки ефективності управління [8].

Кожна 3 сформованих таким чином цілей (підсистем) описується кількісними показниками, що характеризують відповідність СУ функціональному призначенню, такими, як продуктивність (пропускна спроможність), оперативність і якість вирішення завдань управління. При цьому показники нижніх рівнів необхідно використовувати в узагальненому вигляді при обчисленні показників, що знаходяться на верхніх рівнях.

У цьому випадку завдання оцінки ефективності функціонування СУ зводиться до завдання ухвалення рішень 3 декількома показниками, що характеризують якість реалізації функцій системою. Проте реалізація цього підходу для дослідження і оцінки ефективності СУ вимагає встановлення залежності результуючого (комплексного) показника від безлічі часткових, які характеризують відповідність СУ своєму призначенню.

Рішення цієї задачі можна отримати шляхом побудови функції узагальнення показників, задаючи вектор пріоритетів $\mathrm{a}=\left(\mathrm{a}_{1}, \mathrm{a}_{2}, \mathrm{a}_{\mathrm{n}}\right)$ часткових задач [10].

При цьому, взаємозв'язок між елементами різних рівнів ієрархічної системи основних функціональних характеристик встановлюється на основі принципу аддитивної корисності 3 використанням таких співвідношень:

$$
\begin{array}{r}
\mathrm{K}_{1}=\sum_{\mathrm{i}}^{\mathrm{n}} \alpha_{1 \mathrm{i}} \mathrm{K}_{1+1, \mathrm{i}} \\
\sum_{\mathrm{i}} \alpha_{1 \mathrm{i}}=1
\end{array}
$$

де $\mathrm{K}_{1}$ - комплексний показник ефективності функціонування СУ 1 -го рівня;

$\alpha_{1 i}-$ вектор вагових коефіцієнтів;

1 - кількість рівнів декомпозиції;

$\mathrm{n}$ - кількість і -х елементів (показників) на 1му рівні;

$\mathrm{K}_{1+1, \mathrm{i}}-$ нормований вектор часткових показників якості функціонування СУ 1+1-го рівня, кожен елемент якого визначається відповідно до виразу:

$$
\begin{aligned}
& \mathrm{K}_{1+1, \mathrm{i}}=\frac{\mathrm{W}_{1+1, \mathrm{i}}}{\mathrm{W}_{1+1, \mathrm{i}}^{*}} \\
& \mathrm{~W}_{1+1, \mathrm{i}}^{*} \neq 0
\end{aligned}
$$

де $\mathrm{W}_{1+1, \mathrm{i}}$ - $\mathrm{i}$-й частковий показник $1+1$-го рівня;

$\mathrm{W}_{1+1, \mathrm{i}}^{*}$ максимально можливе (потрібне) значення і-го часткового показника $1+1$-го рівня.

Таким чином, комплексний показник $\mathrm{K}_{1}$ ефективності рішення системою усіх покладених на неї функціональних завдань розраховується як зважена сума з урахуванням важливості завдань і 
визначається точносними, тимчасовими або імовірнісними характеристиками правильного рішення системою окремих задач по відношенню до максимально необхідних (потрібних) значень, що гарантують виконання системою відповідних функцій

\section{Висновки і перспективи подальших досліджень}

Таким чином, система управління ПС ЗСУ складною, ієрархічною системою із численними функціональними зв'язками та завданнями. Питанням дослідження ефективності складних СУ присвячено ряд публікацій. Їх аналіз показує, що в якості методичної основи при проведенні досліджень складних систем нині застосовується методологія системного аналізу, що використовує поняття, концепції, формально-математичний апарат кібернетики i теорії складних систем. Оцінка ефективності систем управління частинами (підрозділами) повинна здійснюватися на основі аналізу специфіки їх функціонування.

Аналіз існуючих підходів до дослідження i оцінки ефективності СУ показав, що нині для оцінки якості управління використовують велике число різнорідних показників.

При цьому, об'єднання декількох показників в один узагальнений дозволяє істотно спростити порівняльну оцінку СУ. До того ж застосування системного підходу для оцінки ефективності управління вимагає проведення змістовного аналізу процесу функціонування і встановлення повного переліку завдань, що стоять перед СУ.

Для оцінювання ефективності управління СУ найбільш прийнятним є комбінований метод якій дозволяє об'єднати практично всі існуючі обчислювальні та необчислювальні показники та внутрішні i зовнішні характеристики складної системи з урахування задач, що на неї покладені.

\title{
Лimepamypa
}

Alimpiev A. Selecting a model of unmanned aerial vehicle to accept it for military purposes with regard to expert data Eastern-European / A. Alimpiev, P. Berdnik, N. Korolyuk, O. Korshets, M. Pavlenko // Journal of Enterprise Technologies ISSN 1729-3774. - 2017. - Vol. 1, No. 9(85). - Р. 53-60. 2.Трюхан О.М. Тактика авіації у локальних війнах та збройних конфліктах: досвід, аналіз, тенденції / Трюхан О.М.// Міністерство оборони України. К.: НАОУ, 2005. - 340 с.3. Стенин А. Грузинский реванш / А. Стенин // Воздушно-космическая оборона. 2009. - № 3(46). - C. 4-15.3. Command and Control of Joint Air Operations. Joint Publication/3-3010, February 2014.4.Синявский В. К. Возможные подходы к созданию автоматизированных систем управления войсками (силами) / В.К. Синявский // Наука и военная безопасность. - 2008. - № 3. - С. 21-27. 5.Тимчасові основи ведення операцій військ (сил) ЗС України. - К. ГШ ЗС України, 2016. - 165 с. 6.Харченко В.П. Обслуговування повітряного руху на цивільних аеродромах України / В.П. Харченко, Г.Ф. Аргунов, О.С. Луппо. - К.: НАУ, 2013. - 244 с. 7.Королюк Н.О. Процедура формалізації даних, які використовуються

при описі процесу управління рухом повітряних об'єктів / Н.О. Королюк, Р.В. Корольов, О.А. Коршець // Збірник наукових праць Харківського національного університету Повітряних Сил. - 2017. - № 4(53). - С. 103-106. 8. Камінський В.В. Аналіз застосування безпілотних літальних апаратів в сучасних збройних конфліктах та АТО на Сході України / В.В. Камінський, В.В. Тюрін, О.А. Корщець, Н.О. Королюк // Наука i оборона. - 2017. - № 3(4). - С. 4-8. 9.Пермяков О.Ю. Роль і місце інформаційних технологій в системі державно-оперативного військового управління 3 точки зору сучасних уявлень / О.Ю. Пермяков, Н.О. Королюк // Третя міжнародна науково-практична конференція застосування космічних та геоінформаційних систем в інтересах національної безпеки та оборони 5 квітня 2018 року. - К.: НУОУ С.81-84. 10.Пермяков О.Ю, Королюк Н.О. Інформаційно - телекомунікаційні технології і сучасна збройна боротьба Науково-технічна конференція молодих учених “Актуальні проблеми інформаційних технологій”, 20-21 листопада 2018 року, Київ: НУОУ - 88 с.

\section{ОБОСНОВАНИЕ КОМПЛЕКСНОГО ПОДХОДА ДЛЯ ОЦЕНКИ ЭФФЕКТИВНОСТИ УПРАВЛЕНИЯ ЧАСТЯМИ И ПОДРАЗДЕЛЕНИЯМИ ВОЗДУШНЫХ СИЛ ВСУ}

\author{
Наталья Александровна Королюк (кандидат технических наук) ${ }^{1}$ \\ Роман Алексеевич Пазинич ${ }^{2}$ \\ Сергей Вячеславович Мельник ${ }^{3}$
}

\author{
${ }^{1}$ Харьковский национальный университет Воздушных Сил имени И. Кожедуба, Харьков \\ ${ }^{2}$ в/ч А1671, Чернигов \\ ${ }^{3}$ в/ч A0351, Киев
}

В статье предложен комплексный подход для оценки эффективности функционирования системы управления подразделениями Воздушных Сил Вооруженных Сил Украины с учетом факторов, влияющих на прочесс функиионирование, выдвигаемых требований, опыта организащии управления. Рекомендовано задачу оценки эффективности функиионирования системы управления рассматривать как процесс принятия решений по нескольким показателям. Однако реализация этого подхода предполагает установление зависимости результирующего показателя от множества частньх показателей. Обоснован комплексный показатель эффективности решения системой всех возложенных на нее функииональных задач, который определяется точностными, временными или вероятностными характеристиками правильного решения.

Ключевые слова: эффективность управления, обобщенный показатель качества управления, дерево ичелей, системы управления. 

PART MANAGEMENT UNITS OF AIR FORCES OF THE ARMED FORCES

\author{
Nataliia Koroliuk(Candidate of technical sciences) ${ }^{1}$ \\ Roman Pazynych ${ }^{2}$ \\ Sergii Melnyk ${ }^{3}$ \\ ${ }^{1}$ Of Ivan Kozhedub Kharkiv National Air Force University \\ ${ }^{2}$ Military unit A1671, Chernigiv \\ ${ }^{3}$ Military unit A0351, Kyiv
}

The article proposes a comprehensive approach for assessing the effectiveness of the control system of the units of the Air Forces of the Armed Forces of Ukraine, taking into account the factors influencing the functioning of the process, the demands advanced, and the experience of management organization. The task of evaluating the effectiveness of the management system is recommended as a decision-making process on several indicators. However, the realization of this approach involves the formation of the dependence of the result on a variety of private indicators. The complex indicator of the efficiency of the solution of the system of all the functions assigned to it on a functional basis is proved, which is determined by the exact, temporal or probabilistic characteristics of the correct solution. he control system of the Air Forces of the Armed Forces is a complex, hierarchical system with numerous functional connections and tasks. The issue of the study of the effectiveness of complex SU is devoted to a number of publications. Their analysis shows that methodology of system analysis, using concepts and concepts, the formal-mathematical apparatus of cybernetics and the theory of complex systems, is used as a methodological basis for the research of complex systems. The assessment of the effectiveness of the management system by parts (subdivisions) should be based on the provisions of the experimental and theoretical method. The analysis of existing approaches to the study and evaluation of the effectiveness of the management system showed that today a large number of heterogeneous indicators are used to assess the quality of management. At the same time, combining several indicators into one generalization allows to significantly simplify the comparative estimation of management system.

Keywords: efficiency of management, generalized index of quality of management, tree of goal, management system.

\section{References}

1.Alimpiev, A., Berdnik, P., Korolyuk, N., Korshets, O. and Pavlenko, M. (2017), Selecting a model of unmanned aerial vehicle to accept it for military purposes with regard to expert data Eastern-European, Journal of Enterprise Technologies ISSN 1729-377, Vol. 1, No. 9(85), pp. 5360.2.Tryuxan, O.M. (2005), "Taktyka aviaciyi u lokalnyx vijnax ta zbrojnyx konfliktax: dosvid, analiz, tendenciyi", [Tactics av_atsii at local viynah that martial conflicts: dosvid, analiz, trends], Ministry of Defence Ukraine, NAOU, Kyiv, 340 p.3.Stenyn, A. (2009), "Gruzynskyj revansh" [Georgian revenge], Aerospace Defense, No 3(46),.pp. 415.4.(2014), Command and Control of Joint Air Operations. Joint Publication/3-3010, February 2014.5.Synyavskyj,V.K. (2008), "Vozmozhnuj podxod k ocenke effektyvnosty systemy upravlenyiya vojskamy (sylamy)" [Possible approach to assessing the effectiveness of the control system of troops (forces)] Science and military security, No 3, pp. 21-27.6. (2016), "Tymchasovi osnovy vedennya operacij vijsk (syl) ZS Ukrayiny" [Temporary bases for conducting operations of the Army (forces) of the Armed Forces of Ukraine], General Staff of the Armed Forces of Ukraine, Kyiv, 165 p.7. Xarchenko, V.P., Argunov, G.F. and Luppo, O.Ye. (2013), "Obslugovuvannya povitryanogo ruxu na cyvilnyx aerodromax Ukrayiny" [Air traffic service on civil airfields of April 5, 2018], NUOU, Kyiv, pp. 81-84. 11. Permyakov, O.Y. and Korolyuk, N.O. (2018), "Informacijno - telekomunikacijni texnologiyi $i$ suchasna zbrojna borotba Naukovo-texnichna konferenciya molodyx uchenyx "Aktualni problemy informacijnyx texnologij" 20-
21 lystopada 2018 roku" [Information Ukraine], NAU, Kyiv, 244 p.8. Korolyuk, N.O., Korolov, R.V. and Korshecz, O.A. (2017), "Procedura formalizaciyi danyx, yaki vykorystovuyutsya pry opysi procesu upravlinnya ruxom povitryanyx obyektiv" [The procedure for formalizing data used to describe the process of controlling the movement of airobjects], Communication, radio engineering, acoustics and navigation, No. 4(53), pp. 103-106. 9.Kaminskyj, V.V., Tyurin, V.V., Korshhecz, O.A. and Korolyuk, N.O. (2017), "Analiz zastosuvannya bezpilotnyx litalnyx aparativ $v$ suchasnyx zbrojnyx konfliktax ta ATO na Sxodi Ukrayiny", [Analysis of the use of unmanned aerial vehicles in modern armed conflicts and ATO in the East of Ukraine], Science and defense, No. 3(4), pp. 4-8. 10.Permyakov, O.Y.. and Korolyuk, N.O. (2018), "Rol $i$ misce informacijnyx texnologij $v$ systemi derzhavno-operatyvnogo vijskovogo upravlinnya z tochky zoru suchasnyx uyavlen. Tretya mizhnarodna naukovo-praktychna konferenciya zastosuvannya kosmichnyx ta geoinformacijnyx system $v$ interesax nacionalnoyi bezpeky ta oborony 5 kvitnya 2018 roku" [The role and place of information technology in the system of state operational military management from the point of view of modern ideas Third international scientific and practical conference on the use of space and geoinformation systems in the interests of national security and defense and Telecommunication Technologies and Modern Armed Forces Scientific and Technical Conference of Young Learners "Actual Problems of Information Technologies”, November 20-21, 2018], NUOU, Kyiv, 88 p. 